\title{
Sarcopenia is associated with insomnia in Japanese older adults: a cross-sectional study of data from the Nagasaki Islands study
}

Yuki Nagaura ${ }^{1}$, Hideaki Kondo ${ }^{1,2^{*}}$, Mako Nagayoshi ${ }^{3,4}$ and Takahiro Maeda ${ }^{1,3}$

\begin{abstract}
Background: Sarcopenia is associated with increased mortality among older adults. Sleep-related problems have been studied as factors related to sarcopenia. This study was conducted to determine the relationship between sleep-related problems and sarcopenia among Japanese community-dwelling older adults using data from the Nagasaki Islands Study.

Methods: This cross-sectional study analyzed data collected from 2017 to 2018. A total of 1592 older adults (575 men, 36.1\%) aged 65 years or older participated. Sarcopenia was evaluated using the skeletal muscle mass index and grasp powers based on the criteria of the Asian Working Group for Sarcopenia. Odds ratios for sarcopenia were calculated using logistic regression analysis. Furthermore, subgroup analysis was performed based on the following tertiles of age: $65-70$ years, $71-78$ years, and $79-98$ years.

Results: The number of participants with sarcopenia was 238 (14.9\%). The median age of participants in the sarcopenia group (80 years; interquartile range: 74-84) was significantly higher than in the non-sarcopenia group (73 years; interquartile range 69-79; $P<0.001$ ). In the sarcopenia group, 70.9\% of participants had difficulty initiating and/or maintaining sleep, sleep duration tended to be longer $(P<0.001)$, and 33.3\% of participants' sleep duration was over $9 \mathrm{~h}$. In a logistic regression analysis for sarcopenia, advancing age was the most prominent factor, and the adjusted odds ratio (95\% confidence interval) of facing difficulty initiating and/or maintaining sleep was 1.60 (1.142.25). Despite longer sleep duration being a significant factor in the univariable analysis, it was not significant in the multivariable analysis. In the logistic regression analysis for sarcopenia among older adults aged 79-98 years, the odds ratio (95\% confidence interval) among women was significantly low at $0.53(0.33-0.83)$.
\end{abstract}

Conclusions: Sarcopenia is associated with difficulty initiating and/or maintaining sleep among Japanese older adults. In sarcopenia control measures, sleep/wake disorders related to insomnia are required to be evaluated in detail to help inform nursing and medical policy.

Keywords: Insomnia, Japanese, sarcopenia, Sleep duration

\footnotetext{
* Correspondence: kondo.hideaki.gb@u.tsukuba.ac.jp

'Department of General Medicine, Nagasaki University Graduate School of Biomedical Sciences, Nagasaki, Japan

${ }^{2}$ International Institute for Integrative Sleep Medicine, University of Tsukuba,

1-2 Kasuga, Tsukuba, Ibaraki 305-8550, Japan

Full list of author information is available at the end of the article
}

(c) The Author(s). 2020 Open Access This article is licensed under a Creative Commons Attribution 4.0 International License, which permits use, sharing, adaptation, distribution and reproduction in any medium or format, as long as you give appropriate credit to the original author(s) and the source, provide a link to the Creative Commons licence, and indicate if changes were made. The images or other third party material in this article are included in the article's Creative Commons licence, unless indicated otherwise in a credit line to the material. If material is not included in the article's Creative Commons licence and your intended use is not permitted by statutory regulation or exceeds the permitted use, you will need to obtain permission directly from the copyright holder. To view a copy of this licence, visit http://creativecommons.org/licenses/by/4.0/. The Creative Commons Public Domain Dedication waiver (http://creativecommons.org/publicdomain/zero/1.0/) applies to the data made available in this article, unless otherwise stated in a credit line to the data. 


\section{Background}

Sarcopenia is an age-related decline in skeletal muscle mass as well as muscle function. In a rapidly growing aging society, it is recognized as a significant factor for increased mortality [1]; thus, further clarification of the pathophysiology related to sarcopenia and the development of effective therapeutic interventions are needed in medical and nursing policy.

Sleep-related problems have been studied as factors related to sarcopenia. Some epidemiologic studies including older adults demonstrate that shorter and longer sleep time correlate with sarcopenia [2-6]. Additionally, decreased sleep quality among women, including prolonged sleep latency and day-time dysfunction, is associated with sarcopenia [7, 8]. Moreover, a tendency for delayed sleep phase and an eveningness chronotype are related to sarcopenia [7, 9].

In the common pathophysiological background of sarcopenia and sleep-related problems, the physiological relevance of myokine, a physiologically active substance derived from skeletal muscle, is important. A low level of irisin, one of the myokines, is associated with sarcopenia [10]. Fibronectin type III domain-containing protein 5, a precursor of irisin, is induced during exercise and cleaved and secreted from muscle as irisin. Irisin is involved in the synthesis of brain-derived neurotrophic factor (BDNF) in the hippocampus and contributes to memory improvement [11, 12]. Experimental evidence suggests that BDNF induces increased slow wave activity during sleep; cortical unilateral microinjection of BDNF induces higher slow wave activity in the injected hemisphere, compared to the contralateral one; and blocking the BDNF pathway suppresses local slow wave activity during sleep [13].

Further, the BDNF blood concentration of middleaged adults with insomnia is lower than those of healthy adults, and the severity of insomnia is negatively correlated with BDNF value [14]. Although the role of myokine on the pathophysiology of sarcopenia remains unclear, it is hypothesized that the low level of irisin induces a decrease in BDNF synthesis and is related to the pathophysiology of insomnia in sarcopenia.

The results of previous basic research explain the pathophysiology of insomnia induced by sarcopenia; a mutual relationship between sarcopenia and insomnia is postulated to play a significant role in this condition. However, no studies refer to the relationship between the symptoms of insomnia and sarcopenia. Further, among Japanese community-dwelling older adults, the association between sleep-related problems and sarcopenia is unknown. This study was conducted to determine the relationship between sleep related problems and sarcopenia using data from the Nagasaki Islands Study (NaIS) performed in Goto City, where nearly $40 \%$ of adults are aged 65 years or greater.

\section{Methods}

\section{Participants}

The NaIS is a prospective cohort study that has been performed since 2014 in Goto City in the Nagasaki prefecture, located on the western edge of Japan. The participants were recruited upon medical check-ups, and members of the general population aged 40 years or greater living in Goto City were targeted for enrollment. The recruitment process has been described elsewhere [15]. The present cross-sectional study was conducted in 2019 using data collected from May 2017 to June 2018, when the evaluation of sarcopenia was possible owing to the introduction of body composition analysis. Among the 2246 participants enrolled in the NaIS, the number of older adults aged 65 years or greater was 1637. A total of 45 participants were excluded from analysis in the current study. These included 40 participants whom body composition analysis was not performed, 4 whom grasp power was not performed, and 1 whom body composition analysis and grasp power were not performed. Consequently, a total of 1592 participants (575 men, 36.1\%) were analyzed in the current study (Fig. 1). Approval for this study was granted by the Ethics Committee of Nagasaki University Graduate School of Biomedical Sciences (approval no. 14051404-8). Written informed consent was obtained from all participants.

\section{Survey and collection methods}

Trained interviewers obtained information on the participants' demographic and clinical characteristics, including sex, smoking status, drinking status, comorbidities, and care-related problems. Habitual drinkers were defined as people with a frequency of drinking $\geq 2$ days per week and an alcohol intake $\geq 20 \mathrm{~g}$ of ethanol per day. Care-related problems were obtained in the following areas: staying at home all day, no outings, no hobbies, weakening of neighbor relations, weakening of human relations, falls, no long-distance walking, visual disturbance, stumbling, fear of falling, recent hospitalization, appetite loss, chewing difficulty, weight reduction, and muscle and fat wasting.

The symptoms of insomnia, including difficulty initiating sleep (DIS) and difficulty maintaining sleep (DMS), were assessed. Participants who had any of the symptoms were defined as having difficulty initiating and/or maintaining sleep (DIMS). Sleep duration was calculated from light-out time and get-up time.

Psychological distress was assessed using the Japanese version of the 6-item Kessler Psychological distress scale (K6). The score of each item ranges from 0 to 4 , with global scores ranging from 0 to 24 . The cut-off point for anxiety/emotional disorders screening was estimated at 


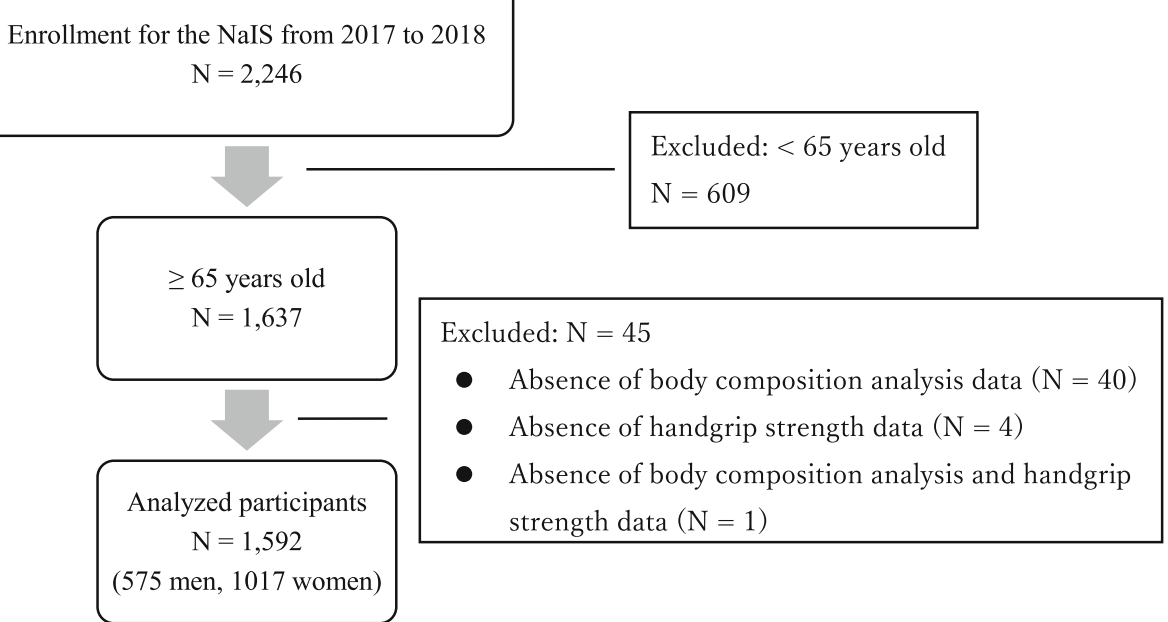

Fig. 1 Flowchart showing how the analyzed participants were selected. Abbreviations: NalS Nagasaki Islands Study

$4 / 5$ with a sensitivity of $76-100 \%$ and specificity of $69-$ $80 \%[16,17]$.

A tendency toward malnutrition was defined as a body mass index $(B M I) \leq 20 \mathrm{~kg} / \mathrm{m}^{2}$, for which a higher risk of mortality has been statistically observed in Japanese older adults [18]. Blood pressure at rest was measured using the cuff oscillometric method with a PASERA AVE-1500 (Shisei Datum, Tokyo, Japan). Individuals were considered as having hypertension if they had a systolic blood pressure of $\geq 140 \mathrm{mmHg}$ and/or diastolic blood pressure of $\geq 90 \mathrm{mmHg}$, if they took blood pressure-lowering medications. Individuals were considered as having diabetes if their hemoglobin was $\mathrm{A} 1 \mathrm{c} \geq$ $6.5 \%$ or if they took blood glucose lowering medications. Individuals were considered as having dyslipidemia if their HDL-cholesterol was $<40 \mathrm{mg} / \mathrm{dl}$ or of if they took cholesterol- and/or triglyceride-lowering medications. The severity of chronic kidney disease was categorized into 5 categories based on the estimated glomerular filtration rate: G1-5 (G1 $\geq 90, \mathrm{G} 2$ 60-89, G3 30-59, G4 $15-29$, G5 $\left.<15 \mathrm{~mL} / \mathrm{min} / 1.73 \mathrm{~m}^{2}\right)[19]$.

Measurement of handgrip strength was performed twice in each hand and mean strength was calculated. Skeletal muscle mass (SMM) was measured by using bioelectrical impedance analysis with an InBody 770 (InBody Japan, Tokyo, Japan). Skeletal muscle mass index (SMI) was calculated as follows: $\mathrm{SMI}=\mathrm{SMM}$ / height ${ }^{2}\left(\mathrm{~kg} / \mathrm{m}^{2}\right)$ [20]. Sarcopenia was defined using the cut-off points of handgrip strength and SMI, but not gait speed, based on the criteria of the Asian Working Group for Sarcopenia (AWGS) as having both lower handgrip strength and lower SMI: handgrip strength (men $<26 \mathrm{~kg}$; women $<18 \mathrm{~kg}$ ) and SMI (men $\leq 7 \mathrm{~kg} / \mathrm{m}^{2}$; women $\leq 5.7 \mathrm{~kg} / \mathrm{m}^{2}$ ) [21].

\section{Statistical analysis}

$\mathrm{R}$ version 3.5.2 (https://www.r-project.org/) and EZR version 1.40 (http://www.jichi.ac.jp/saitama-sct/SaitamaHP. files/statmed.html) were used for statistical analysis [22]. Continuous variables were presented as medians and interquartile ranges (IQR) where non-normally distributed. Comparisons of continuous variables were performed using Mann-Whitney U test. Categorical variables were presented as counts and percentages. Frequency analyses for categorical data were performed using Fisher's exact test. The two-sided alpha level was set at 0.05.

Odds ratios (ORs) for sarcopenia were calculated via logistic regression analysis with sarcopenia as a dependent variable. The following were used as independent variables: age, sex, BMI, IHD, DIMS, sleep duration, and care related problems, including appetite loss, no hobbies, recent hospitalization, weakening of neighbor relations, visual disturbance, and without longdistance walking. Age was categorized based on the following quartiles: $\leq 68$ years (reference group; ref), 69-73 years, $74-79$ years, and $\geq 80$ years. BMI was categorized into three groups: $\leq 20 \mathrm{~kg} / \mathrm{m}^{2}, 20-25 \mathrm{~kg} / \mathrm{m}^{2}$ (ref), and > $25 \mathrm{~kg} / \mathrm{m}^{2}$. Smoking was categorized into three groups: never (ref), current smoker, and ex-smoker. Sleep duration was categorized into 5 groups: $<6 \mathrm{~h}, 6-7 \mathrm{~h}, 7-8 \mathrm{~h}$ (ref), 8-9h, and $\geq 9 \mathrm{~h}$. The global score of $\mathrm{K} 6$ was categorized into two groups: $<5$ (ref) and $\geq 5$ (psychological distress group).

Sarcopenia and insomnia are prevalent with advancing age. Therefore, subgroup analysis was performed based on the following tertiles of age: $65-70$ years, $71-78$ years, and 79-98 years. In the second set logistic regression analyses for sarcopenia stratified by tertiles of age, the independent variables were sex, BMI, and DIMS. 


\section{Results}

Table 1 and Additional file 1 (Table S1) show the demographic and clinical characteristics. The number of participants with sarcopenia was 282 (17.7\%). The median age (interquartile range) of participants with sarcopenia was significantly higher than that of participants without sarcopenia: 79 (74-84) years vs. $73(68-78)$ years, respectively $(P<0.001)$. Among the sarcopenia group, a tendency toward spending a longer sleep duration was observed and the percentage of sleep duration $\geq 9 \mathrm{~h}$ was $32.0 \%(P<0.001)$. Compared to the non-sarcopenia group, the percentages of DIS and DMS among participants in the sarcopenia group were significantly higher ( $P=0.005$ and $P<0.001$, respectively), and the percentage of DISM in the sarcopenia group reached $69.0 \%$ (Table 2). Care-related problems in the sarcopenia group were prevalent; specifically, no hobbies, no long-distance walking $(\geq 1 \mathrm{~km})$, and appetite loss showed higher percentages $(P<0.001$; Table 3$)$. In the logistic regression analysis for sarcopenia, advancing age was the most prominent factor, and the adjusted OR (95\% confidence interval; CI) of having DIMS was 1.56 (1.14-2.13).

Table 1 Demographic and sleep-related characteristics

\begin{tabular}{|c|c|}
\hline $\bar{N}$ & 1592 \\
\hline Sex, Men, n (\%) & $575(36.1)$ \\
\hline Age, median (IQR) & $74(69-80)$ \\
\hline $\mathrm{BMI} \mathrm{kg} / \mathrm{m}^{2}$, median $(\mathrm{IQR})$ & $22.7(20.6-24.9)$ \\
\hline $\mathrm{BMI} \leq 20 \mathrm{~kg} / \mathrm{m}^{2}, \mathrm{n}(\%)$ & $319(20.0)$ \\
\hline BMI $20-25$ kg/m², n (\%) & $894(56.2)$ \\
\hline $\mathrm{BMI}>25 \mathrm{~kg} / \mathrm{m}^{2}, \mathrm{n}(\%)$ & $379(23.8)$ \\
\hline Habitual drinker, n (\%) & $38(2.4)$ \\
\hline \multicolumn{2}{|l|}{ Smoking status } \\
\hline Never, n (\%) & $1117(70.2)$ \\
\hline Past, n (\%) & $369(23.2)$ \\
\hline Current, n (\%) & $106(6.7)$ \\
\hline \multicolumn{2}{|l|}{ Sleep duration } \\
\hline$<6 \mathrm{~h}, \mathrm{n}(\%)$ & $79(5.0)$ \\
\hline $6-7$ h, n (\%) & $216(13.6)$ \\
\hline $7-8$ h, n (\%) & $429(27.0)$ \\
\hline $8-9$ h, n (\%) & $482(30.3)$ \\
\hline$\geq 9$ h, n (\%) & $385(24.2)$ \\
\hline \multicolumn{2}{|l|}{ Insomnia symptoms } \\
\hline DIS, n (\%) & $432(27.2)$ \\
\hline DMS, n (\%) & $592(37.2)$ \\
\hline DIMS, n (\%) & $844(53.0)$ \\
\hline K6 global score $\geq 5, \mathrm{n}(\%)$ & $134(8.4)$ \\
\hline
\end{tabular}

Abbreviations: $B M I$ body mass index, DIS difficulty initiating sleep, DIMS difficulty initiating and/or maintaining sleep, DMS difficulty maintaining sleep, $I Q R$ interquartile range
Table 2 Comparison of demographic and sleep-related characteristics between non-sarcopenia group and sarcopenia group

\begin{tabular}{|c|c|c|c|}
\hline & Non-sarcopenia & Sarcopenia & $P$ value \\
\hline $\bar{N}$ & 1310 & 282 & \\
\hline Male, n (\%) & $482(36.8)$ & $93(33.0)$ & 0.25 \\
\hline Age years, median (IQR) & $73.0(68.0-78.0)$ & $79.0(74.0-84.0)$ & $<0.001$ \\
\hline 65-68, n (\%) & $431(32.9)$ & $26(9.2)$ & $<0.001$ \\
\hline 69-73, n (\%) & $326(24.9)$ & $56(19.9)$ & \\
\hline 74-79, n (\%) & $332(25.3)$ & $80(28.4)$ & \\
\hline$>80, \mathrm{n}(\%)$ & $221(16.9)$ & $120(42.6)$ & \\
\hline BMI kg/m², median (IQR) & $23.1(21.0-25.2)$ & $20.7(19.0-22.7)$ & $<0.001$ \\
\hline $\mathrm{BMI} \leq 20 \mathrm{~kg} / \mathrm{m}^{2}, \mathrm{n}(\%)$ & $208(15.9)$ & $111(39.4)$ & $<0.001$ \\
\hline BMI $20-25$ kg/m², n (\%) & $753(57.5)$ & $141(50.0)$ & \\
\hline $\mathrm{BMI}>25 \mathrm{~kg} / \mathrm{m}^{2}, \mathrm{n}(\%)$ & $349(26.6)$ & $30(10.6)$ & \\
\hline Habitual drinker, n (\%) & $35(2.7)$ & $3(1.1)$ & 0.13 \\
\hline \multicolumn{4}{|l|}{ Smoking status } \\
\hline Never, n (\%) & $909(69.4)$ & $208(73.8)$ & 0.29 \\
\hline Past, n (\%) & $309(23.6)$ & $60(21.3)$ & \\
\hline Current, n (\%) & $92(7.0)$ & $14(5.0)$ & \\
\hline \multicolumn{4}{|l|}{ Sleep duration } \\
\hline$<6 \mathrm{~h}, \mathrm{n}(\%)$ & $70(5.3)$ & $9(3.2)$ & $<0.001$ \\
\hline $6-7$ h, n (\%) & $190(14.5)$ & $26(9.3)$ & \\
\hline $7-8$ h, n (\%) & $366(27.9)$ & $63(22.4)$ & \\
\hline $8-9$ h, n (\%) & $389(29.7)$ & $93(33.1)$ & \\
\hline$\geq 9 \mathrm{~h}, \mathrm{n}(\%)$ & $295(22.5)$ & $90(32.0)$ & \\
\hline \multicolumn{4}{|l|}{ Insomnia symptoms } \\
\hline DIS, n (\%) & $336(25.7)$ & $96(34.2)$ & 0.005 \\
\hline DMS, n (\%) & $452(34.5)$ & $140(49.6)$ & $<0.001$ \\
\hline DIMS, n (\%) & $650(49.6)$ & $194(69.0)$ & $<0.001$ \\
\hline K6 global score $\geq 5, \mathrm{n}(\%)$ & $102(7.8)$ & $32(11.3)$ & 0.06 \\
\hline
\end{tabular}

Abbreviations: $B M I$ body mass index, DIS difficulty initiating sleep, DIMS difficulty initiating and/or maintaining sleep, DMS difficulty maintaining sleep, $I Q R$ interquartile range

Moreover, longer sleep duration was a significant factor in the univariable analysis, but it was not significant in the multivariable analysis (Table 4).

In the subgroup analysis stratified by tertile of age, the numbers of participants with sarcopenia among older adults aged $65-70,71-78$, and $79-98$ years were 32 (5.8\%), 103 (18.0\%) and 147 (31.2\%; Additional file 1: Table S2-4), respectively. The percentages of sarcopenia with DIMS among older adults aged $65-70,71-78$, and 79-98 years were $3.6,10.5$, and $24.3 \%$, respectively (Fig. 2). The ORs (95\% CI) of having DIMS among older adults aged $65-70,71-78$, and $79-98$ years for sarcopenia were 2.25 (1.06-4.75), $1.48(0.93-2.34)$, and 2.07 (1.28-3.33), respectively (Table 5$)$. 
Table 3 Comparison of care-related problems and clinical characteristics between non-sarcopenia group and sarcopenia group

\begin{tabular}{|c|c|c|c|}
\hline & Non-sarcopenia & Sarcopenia & $P$ value \\
\hline $\bar{N}$ & 1310 & 282 & \\
\hline \multicolumn{4}{|l|}{ Care-related problems } \\
\hline $\begin{array}{l}\text { Staying at home all day, } \\
\mathrm{n}(\%)\end{array}$ & $151(11.5)$ & $57(20.2)$ & $<0.001$ \\
\hline No outing, n (\%) & $52(4.0)$ & $25(8.9)$ & 0.001 \\
\hline No hobbies, n (\%) & $189(14.4)$ & $67(23.8)$ & $<0.001$ \\
\hline $\begin{array}{l}\text { Weakening of neighbor } \\
\text { relations, } \mathrm{n}(\%)\end{array}$ & $219(16.7)$ & $66(23.4)$ & 0.01 \\
\hline $\begin{array}{l}\text { Weakening of human } \\
\text { relations, n (\%) }\end{array}$ & $132(10.1)$ & $40(14.2)$ & 0.056 \\
\hline Falls, n (\%) & $218(16.7)$ & $59(20.9)$ & 0.1 \\
\hline $\begin{array}{l}\text { No long-distance walking, } \\
\text { n (\%) }\end{array}$ & $213(16.3)$ & $90(31.9)$ & $<0.001$ \\
\hline Visual disturbance, n (\%) & $33(2.5)$ & $15(5.3)$ & 0.02 \\
\hline Stumbling, n (\%) & $162(12.4)$ & $42(14.9)$ & 0.28 \\
\hline Fear of falling, $\mathrm{n}(\%)$ & $10(0.8)$ & $10(3.5)$ & 0.001 \\
\hline Recent hospitalization, n (\%) & $136(10.4)$ & $46(16.3)$ & 0.007 \\
\hline Appetite loss, n (\%) & $32(2.4)$ & $22(7.8)$ & $<0.001$ \\
\hline Chewing difficulty, n (\%) & $55(4.2)$ & $18(6.4)$ & 0.12 \\
\hline Weight reduction, n (\%) & $85(6.5)$ & $30(10.7)$ & 0.02 \\
\hline Muscle and fat wasting, n (\%) & $252(19.2)$ & $78(27.7)$ & 0.002 \\
\hline Hypertension, n (\%) & $803(61.3)$ & $182(64.5)$ & 0.34 \\
\hline Diabetes, n (\%) & 361 (27.6) & $64(22.7)$ & 0.1 \\
\hline Dyslipidemia, n (\%) & $372(28.4)$ & $72(25.5)$ & 0.34 \\
\hline Ischemic heart disease, n (\%) & $98(7.6)$ & $38(13.6)$ & 0.002 \\
\hline Stroke, n (\%) & $69(5.4)$ & $19(6.8)$ & 0.39 \\
\hline \multicolumn{4}{|l|}{ Chronic kidney disease } \\
\hline G1, n (\%) & $87(6.6)$ & $31(11.0)$ & 0.005 \\
\hline G2, n (\%) & $852(65.0)$ & $156(55.3)$ & \\
\hline G3, n (\%) & $366(27.9)$ & $95(33.7)$ & \\
\hline G4-5, n (\%) & $5(0.4)$ & $0(0.0)$ & \\
\hline
\end{tabular}

\section{Discussion}

This study is the first to examine the relationship between sarcopenia and insomnia among Japanese community-dwelling older adults. Some previous studies have focused on the relationship between sarcopenia and sleep duration. In the present multivariable analysis, however, DIMS was a significant factor, rather than sleep duration. Although decreased subjective sleep quality, prolonged sleep latency, and tendency of delayed sleep phase are reported to be associated with sarcopenia [7-9], there is no study that specifically explores DIMS and sarcopenia.

In the present study, there were few participants with a short sleep duration. Only 22 participants (1.4\%) had a
Table 4 Logistic regression analysis for sarcopenia as a dependent variable

\begin{tabular}{|c|c|c|}
\hline Independent variable & $\begin{array}{l}\text { Univariable } \\
\text { analysis } \\
\text { Odds ratio } \\
(95 \% \mathrm{Cl})\end{array}$ & $\begin{array}{l}\text { Multivariable } \\
\text { analysis } \\
\text { Odds ratio } \\
(95 \% \mathrm{Cl})\end{array}$ \\
\hline \multicolumn{3}{|l|}{ Age } \\
\hline 65-68(reference) & 1 & 1 \\
\hline $69-73$ & $2.85(1.75-4.63)$ & $3.13(1.86-5.28)$ \\
\hline $74-79$ & $3.99(2.51-6.36)$ & $3.72(2.23-6.20)$ \\
\hline$>80$ & $9.00(5.72-14.20)$ & $7.79(4.63-13.10)$ \\
\hline Female (vs. Male) & $1.18(0.90-1.55)$ & $1.11(0.81-1.51)$ \\
\hline \multicolumn{3}{|l|}{ BMI } \\
\hline$\leq 20 \mathrm{~kg} / \mathrm{m} 2$ & $2.85(2.13-3.82)$ & $3.33(2.39-4.63)$ \\
\hline 20-25 kg/m2(reference) & 1 & 1 \\
\hline$>25 \mathrm{~kg} / \mathrm{m} 2$ & $0.46(0.30-0.70)$ & $0.46(0.29-0.71)$ \\
\hline IHD (vs. non-IHD) & $1.91(1.28-2.84)$ & $1.49(0.95-2.34)$ \\
\hline \multicolumn{3}{|l|}{ Care-related problems } \\
\hline Appetite loss & $3.37(1.93-5.90)$ & $2.04(1.04-4.01)$ \\
\hline No hobbies & $1.85(1.35-2.53)$ & $1.77(1.21-2.57)$ \\
\hline Recent hospitalization & $1.68(1.17-2.42)$ & $1.40(0.92-2.12)$ \\
\hline Weakening of neighbor relations & $1.52(1.11-2.08)$ & $1.27(0.88-1.84)$ \\
\hline Visual disturbance & $2.18(1.17-4.07)$ & $1.20(0.59-2.43)$ \\
\hline Without long-distance walking & $2.41(1.81-3.23)$ & $1.39(0.97-2.00)$ \\
\hline DIMS (vs. non-DIMS) & $2.26(1.72-2.98)$ & $1.56(1.14-2.13)$ \\
\hline \multicolumn{3}{|l|}{ Sleep duration } \\
\hline$<6 \mathrm{~h}$ & $0.75(0.36-1.57)$ & $0.95(0.42-2.14)$ \\
\hline $6-7 h$ & $0.80(0.49-1.30)$ & $0.94(0.55-1.62)$ \\
\hline $7-8 \mathrm{~h}$ & 1 & 1 \\
\hline $8-9 h$ & $1.39(0.98-1.97)$ & $1.11(0.75-1.64)$ \\
\hline$\geq 9 \mathrm{~h}$ & $1.77(1.24-2.53)$ & $1.21(0.81-1.81)$ \\
\hline
\end{tabular}

sleep duration $<5 \mathrm{~h}$, and 79 participants (5\%) had a sleep duration $<6 \mathrm{~h}$. The relationship between short sleep duration and sarcopenia was reported in three previous studies $[2,3,5]$. Two of the studies examined the relationship among adults aged 40 years or greater, and the participants were not restricted to older adults $[2,3]$. Therefore, more large-scale examination is required to determine the relationship between short sleep duration and sarcopenia among older adults.

In the present study, although a sleep duration $\geq 9 \mathrm{~h}$ was associated with sarcopenia in univariable analysis, long sleep duration was not a significant factor in multivariable analysis. Long sleep duration is reported to be associated with sarcopenia [2-6]. In an epidemiological study without using polysomnography, sleep duration is not necessarily the actual sleep duration. Particular 


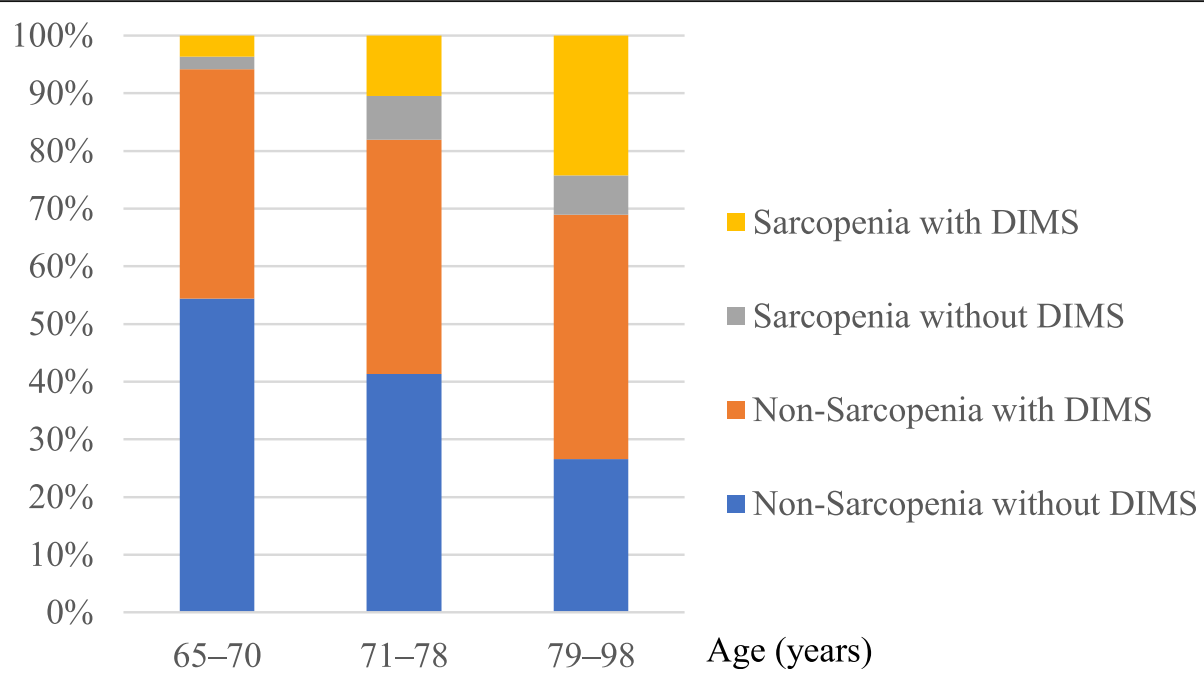

Fig. 2 Percentage of sarcopenia and DIMS stratified by tertile of age. Abbreviations: DIMS difficulty initiating and/or maintaining sleep

attention was given to participants with insomnia who spent a long time in bed. In older adults, lower sleep efficiency is frequently observed as a result of increased wake time after sleep onset [23]. In a study in which participants' mean age ( \pm standard deviation; SD) was $41.3 \pm 18.4$ years, self-reported habitual mean $( \pm$ SD) sleep duration was $7.6 \pm 1.6 \mathrm{~h}$, and mean $( \pm$ SD) total sleep time obtained by polysomnography was $6.2 \pm 1.6 \mathrm{~h}$ [24]. In the present study, the percentage of participants with DIMS, especially DMS, increased with a longer sleep duration (Additional file 1: Table S5).

In the general Japanese adult population, the prevalence of DIMS in men and women is reported as 17.3

Table $\mathbf{5}$ Logistic regression analysis, stratified by tertile of age, for sarcopenia as a dependent variable

\begin{tabular}{ll}
\hline Independent variable & $\begin{array}{l}\text { Multivariable analysis } \\
\text { Odds ratio }(95 \% \mathrm{Cl})\end{array}$ \\
\hline 65-70 years & $0.86(0.38-1.94)$ \\
Women (vs. Men) & $0.80(0.70-0.90)$ \\
BMI (increment of $\left.1 \mathrm{~kg} / \mathrm{m}^{2}\right)$ & $2.25(1.06-4.75)$ \\
DIMS (vs. non-DIMS) & \\
71-78 years & $1.61(0.97-2.70)$ \\
Women (vs. Men) & $0.76(0.70-0.83)$ \\
BMI (increment of $\left.1 \mathrm{~kg} / \mathrm{m}^{2}\right)$ & $1.48(0.93-2.34)$ \\
DIMS (vs. non-DIMS) & \\
79-98 years & $0.79(0.51-1.22)$ \\
Women (vs. Men) & $0.75(0.69-0.82)$ \\
BMI (increment of $\left.1 \mathrm{~kg} / \mathrm{m}^{2}\right)$ & $2.07(1.28-3.33)$ \\
DISM (vs. non-DISM) & \\
\hline
\end{tabular}

Abbreviations: $B M I$ body mass index, DIMS difficulty initiating and/or maintaining sleep and $21.5 \%$, respectively. The prevalence increases with advancing age: $60-69,70-79$, and $\geq 80$ years; 21.9 , 20.5 , and $30.5 \%$ in men; 20.3, 26.3, and $40.3 \%$ in women, respectively [25]. In this previous report, DIMS was defined as difficulty initiating sleep within 30 min three or more times a week and/or difficulty maintaining sleep three or more times a week in the last month. In the present study, DIMS was more prevalent than in that previous study, because frequency of insomnia symptoms were not included in the definition of DIMS.

The associations between sarcopenia and DIMS were observed among older adults aged 65-70 and 79-98 years, but not those aged 71-78 years. The increase of sarcopenia surpassed the increase of DISM in the 71-78 years group. In the 65-70 years group, the prevalence of sarcopenia was fewer and the $95 \%$ CI of OR for sarcopenia was wider than the other groups. To be adjust for confounding factors, a larger scale study is required for this group.

In previous studies, insomnia symptoms have not been considered in the evaluation of sleep problems related to sarcopenia among older adults. Future studies should investigate in detail not only chronic insomnia disorder, but also other sleep/wake disorders related to insomnia symptoms, including restless legs syndrome/WillisEkbom disease.

\section{Study limitations}

The present study possesses some limitations of note. Gait speed was not assessed in the present study. The evaluation of physical performance is an important factor to diagnose sarcopenia. Low gait speed and/or low handgrip strength were included in AWGS 2014 criteria. 
Therefore, participants whose gait speed and muscle mass were low, but handgrip strength was within normal range, were classified as the "Non-sarcopenia" group. In AWGS 2019 criteria, either calf circumference (CC) or the SARC-F or SARC-CalF questionnaires is recommended for case-finding, and either 5-time chair stand test or 6-m walk or short physical performance battery is recommended for assessment of physical performance [26]. In the present study, these items were not assessed. Further studies are required based on the AWGS 2019 criteria.

In the present data collection using questionnaires by interviewers, actual total sleep duration could not be confirmed; thus, an objective evaluation using polysomnography is needed to measure total sleep time accurately. Additionally, the severity of insomnia symptoms was not considered. Sleep/wake disorders related to insomnia, including chronic insomnia disorder, sleep disordered breathing, circadian rhythm sleep/wake disorders, restless legs syndrome/WillisEkbom disease, and rapid eye movement sleep behavior disorder were not examined systematically.

Finally, although the relationship between sarcopenia and DIMS was observed, it remains unknown whether insomnia induces sarcopenia in the present crosssectional study. To confirm the effects of insomnia on developing sarcopenia, it is necessary to conduct large prospective cohort studies and longitudinal studies targeting the patients with insomnia.

\section{Conclusions}

Sarcopenia was found to be associated with difficulty initiating and/or maintaining sleep among Japanese community-dwelling older adults. Consequently, in sarcopenia control measures, sleep/wake disorders related to insomnia must be evaluated in detail. Further, basic and clinical studies are needed to elucidate the link between sleep/wake disorders and sarcopenia.

\section{Supplementary information}

Supplementary information accompanies this paper at https://doi.org/10. 1186/s12877-020-01658-w.

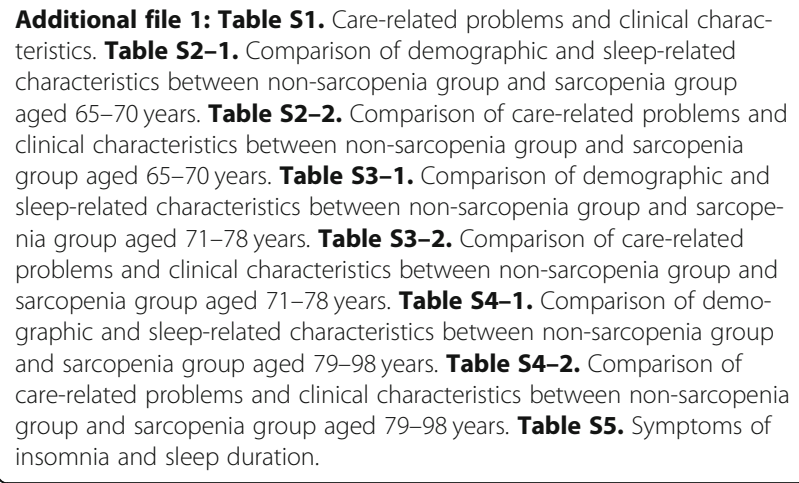

Additional file 1: Table S1. Care-related problems and clinical characteristics. Table S2-1. Comparison of demographic and sleep-related characteristics between non-sarcopenia group and sarcopenia group aged 65-70 years. Table S2-2. Comparison of care-related problems and clinical characteristics between non-sarcopenia group and sarcopenia group aged 65-70 years. Table S3-1. Comparison of demographic and sleep-related characteristics between non-sarcopenia group and sarcopenia group aged 71-78 years. Table S3-2. Comparison of care-related problems and clinical characteristics between non-sarcopenia group and sarcopenia group aged 71-78 years. Table S4-1. Comparison of demographic and sleep-related characteristics between non-sarcopenia group and sarcopenia group aged 79-98 years. Table S4-2. Comparison of care-related problems and clinical characteristics between non-sarcopenia group and sarcopenia group aged 79-98 years. Table S5. Symptoms of insomnia and sleep duration.

\section{Abbreviations}

AWGS: Asian Working Group for Sarcopenia; BDNF: Brain-derived neurotrophic factor; BMI: Body mass index; CC: Calf circumference; Cl: Confidence interval; DIS: Difficulty initiating sleep; DIMS: Difficulty initiating and/or maintaining sleep; DMS: Difficulty maintaining sleep; IHD: Ischemic heart disease; IQR: Interquartile range; K6: Kessler Psychological distress scale; NalS: Nagasaki Islands Study; OR: Odds ratio; SMI: Skeletal muscle mass index; SMM: Skeletal muscle mass

\section{Acknowledgements}

We are grateful to Goto City Office for their assistance in carrying out the NalS and to all the staff involved in the NalS from Nagasaki University Graduate School of Biomedical Sciences for their project management. We sincerely appreciate the older adults who participated in the study for their cooperation.

\section{Authors' contributions}

TM and MN designed the NalS. All authors participated the data collection. YN and HK contributed the statistical analysis and drafted the manuscript. All authors read and approved the final manuscript.

Funding

None.

\section{Availability of data and materials}

The dataset used and/or analyzed during the current study is available from the corresponding author on reasonable request.

\section{Ethics approval and consent to participate}

All procedures performed in studies involving human participants were in accordance with the ethical standards of the institutional and/or national research committee and with the 1964 Helsinki declaration and its later amendments or comparable ethical standards. This study was approved by the Ethics Committee of Nagasaki University Graduate School of Biomedical Sciences (Approval No. 14051404-8). Written informed consent was obtained from all individual participants included in the study.

\section{Consent for publication}

Not applicable.

\section{Competing interests}

The authors declare that they have no competing interest.

\section{Author details}

'Department of General Medicine, Nagasaki University Graduate School of Biomedical Sciences, Nagasaki, Japan. ${ }^{2}$ International Institute for Integrative Sleep Medicine, University of Tsukuba, 1-2 Kasuga, Tsukuba, Ibaraki 305-8550, Japan. ${ }^{3}$ Department of Community Medicine, Nagasaki University Graduate School of Biomedical Sciences, Nagasaki, Japan. ${ }^{4}$ Department of Health Promotion, National Institute of Public Health, Wako, Japan.

Received: 18 December 2019 Accepted: 16 July 2020

Published online: 28 July 2020

\section{References}

1. Liu P, Hao Q, Hai S, Wang H, Cao L, Dong B. Sarcopenia as a predictor of allcause mortality among community-dwelling older people: a systematic review and meta-analysis. Maturitas. 2017;103:16-22.

2. Tan X, Titova OE, Lindberg E, Elmståhl S, Lind L, Schiöth HB, Benedict C. Association between self-reported sleep duration and body composition in middle-aged and older adults. J Clin Sleep Med. 2019;15(3):431-5.

3. Kim RH, Kim Kl, Kim JH, Park YS. Association between sleep duration and body composition measures in Korean adults: the Korea National Health and nutrition examination survey 2010. Korean J Fam Med. 2018; 39(4):219-24.

4. Kwon Y-J, Jang S-Y, Park E-C, Cho AR, Shim J-Y, Linton JA. Long sleep duration is associated with sarcopenia in Korean adults based on data from the 2008-2011 KNHANES. J Clin Sleep Med. 2017;13(9):1097-104.

5. Hu X, Jiang J, Wang H, Zhang L, Dong B, Yang M. Association between sleep duration and sarcopenia among community-dwelling older adults: a cross-sectional study. Medicine (Baltimore). 2017;96(10):e6268. 
6. Chien M-Y, Wang L-Y, Chen H-C. The relationship of sleep duration with obesity and sarcopenia in community-dwelling older adults. Gerontology. 2015;61(5):399-406.

7. Lucassen EA, de Mutsert R, le Cessie S, Appelman-Dijkstra NM, Rosendaal FR, van Heemst D, den Heijer M, Biermasz NR, group NEOs. Poor sleep quality and later sleep timing are risk factors for osteopenia and sarcopenia in middle-aged men and women: the NEO study. PLoS One. 2017;12(5): e0176685.

8. Locquet M, Beaudart C, Delandsheere L, Reginster JY, Bruyere O. Subjective sleep quality among Sarcopenic and non-Sarcopenic older adults: results from the SarcoPhAge cohort. J Frailty Aging. 2018;7(3):176-81.

9. Yu JH, Yun C-H, Ahn JH, Suh S, Cho HJ, Lee SK, Yoo HJ, Seo JA, Kim SG, Choi KM, et al. Evening chronotype is associated with metabolic disorders and body composition in middle-aged adults. J Clin Endocrinol Metab. 2015;100(4):1494-502

10. Park H-S, Kim HC, Zhang D, Yeom H, Lim S-K. The novel myokine irisin: clinical implications and potential role as a biomarker for sarcopenia in postmenopausal women. Endocrine. 2019;64(2):341-8.

11. Choi SH, Bylykbashi E, Chatila ZK, Lee SW, Pulli B, Clemenson GD, Kim E, Rompala A, Oram MK, Asselin C, et al. Combined adult neurogenesis and BDNF mimic exercise effects on cognition in an Alzheimer's mouse model. Science. 2018;361(6406):eaan8821.

12. Wrann CD, White JP, Salogiannnis J, Laznik-Bogoslavski D, Wu J, Ma D, Lin JD, Greenberg ME, Spiegelman BM. Exercise induces hippocampal BDNF through a PGC-1a/FNDC5 pathway. Cell Metab. 2013;18(5):649-59.

13. Faraguna $U$, Vyazovskiy $W$, Nelson $A B$, Tononi $G$, Cirelli C. A causal role for brain-derived neurotrophic factor in the homeostatic regulation of sleep. Neurosci. 2008:28(15):4088-95.

14. Mikoteit T, Brand S, Eckert A, Holsboer-Trachsler E, Beck J. Brain-derived neurotrophic factor is a biomarker for subjective insomnia but not objectively assessable poor sleep continuity. J Psychiatr Res. 2019;110:103-9.

15. Yamanashi $H$, Shimizu Y, Koyamatsu J, Nobuyoshi M, Nagayoshi M, Kadota K, Tamai M, Maeda T. Multiple somatic symptoms and frailty: cross-sectional study in Japanese community-dwelling elderly people. Fam Pract. 2016; 33(5):453-60.

16. Furukawa TA, Kawakami N, Saitoh M, Ono $Y$, Nakane $Y$, Nakamura $Y$, Tachimori H, Iwata N, Uda H, Nakane $\mathrm{H}$, et al. The performance of the Japanese version of the $\mathrm{K} 6$ and $\mathrm{K} 10$ in the world mental health survey Japan. Int J Methods Psychiatr Res. 2008;17(3):152-8.

17. Kessler RC, Andrews G, Colpe LJ, Hiripi E, Mroczek DK, Normand SLT, Walters EE, Zaslavsky AM. Short screening scales to monitor population prevalences and trends in non-specific psychological distress. Psychol Med. 2002;32(6): 959-76.

18. Sasazuki S, Inoue M, Tsuji I, Sugawara Y, Tamakoshi A, Matsuo K, Wakai K, Nagata C, Tanaka K, Mizoue T, et al. Body mass index and mortality from all causes and major causes in Japanese: results of a pooled analysis of 7 largescale cohort studies. J Epidemiol. 2011;21(6):417-30.

19. Matsuo S, Imai E, Horio M, Yasuda Y, Tomita K, Nitta K, Yamagata K, Tomino $Y$, Yokoyama $H$, Hishida A, et al. Revised equations for estimated GFR from serum creatinine in Japan. Am J Kidney Dis. 2009; 53(6):982-92

20. Yamada Y, Nishizawa M, Uchiyama T, Kasahara Y, Shindo M, Miyachi M, Tanaka S. Developing and validating an age-independent equation using multi-frequency bioelectrical impedance analysis for estimation of appendicular skeletal muscle mass and establishing a cutoff for sarcopenia. Int J Environ Res Public Health. 2017;14(7):809.

21. Chen L-K, Liu L-K, Woo J, Assantachai P, Auyeung T-W, Bahyah KS, Chou MY, Chen L-Y, Hsu P-S, Krairit O, et al. Sarcopenia in Asia: consensus report of the Asian working Group for Sarcopenia. J Am Med Dir Assoc. 2014;15(2): 95-101.

22. Kanda Y. Investigation of the freely available easy-to-use software 'EZR' for medical statistics. Bone Marrow Transplant. 2013;48(3):452-8.

23. Ohayon MM, Carskadon MA, Guilleminault C, Vitiello MV. Meta-analysis of quantitative sleep parameters from childhood to old age in healthy individuals: developing normative sleep values across the human lifespan. Sleep. 2004;27(7):1255-73.

24. Patel SR, Zhu X, Storfer-Isser A, Mehra R, Jenny NS, Tracy R, Redline S. Sleep duration and biomarkers of inflammation. Sleep. 2009;32(2): 200-4.
25. Doi Y, Minowa M, Okawa M, Uchiyama M. Prevalence of sleep disturbance and hypnotic medication use in relation to sociodemographic factors in the general Japanese adult population. J Epidemiol. 2000;10(2):79-86.

26. Chen LK, Woo J, Assantachai $P$, Auyeung TW, Chou MY, lijima K, Jang HC, Kang L, Kim M, Kim S, et al. Asian Working Group for Sarcopenia: 2019 Consensus Update on Sarcopenia Diagnosis and Treatment. J Am Med Dir Assoc. 2020;21(3):300-7 e302.

\section{Publisher's Note}

Springer Nature remains neutral with regard to jurisdictional claims in published maps and institutional affiliations.
Ready to submit your research? Choose BMC and benefit from:

- fast, convenient online submission

- thorough peer review by experienced researchers in your field

- rapid publication on acceptance

- support for research data, including large and complex data types

- gold Open Access which fosters wider collaboration and increased citations

- maximum visibility for your research: over $100 \mathrm{M}$ website views per year

At BMC, research is always in progress.

Learn more biomedcentral.com/submissions 